\title{
Surgeon-Patient Information Disclosure Practices in Southwestern Nigeria
}

\author{
T.O. Ogundiran ${ }^{a, b} \quad$ C.A. Adebamowo ${ }^{b-d}$ \\ ${ }^{a}$ Division of Oncology, Department of Surgery, College of Medicine, University of Ibadan and University \\ College Hospital, Ibadan, ${ }^{b}$ West African Bioethics Programme, University of Ibadan, Ibadan, and ${ }^{\mathrm{C}}$ Institute of \\ Human Virology, Abuja, Nigeria; ${ }^{d}$ Department of Epidemiology and Preventive Medicine, University of Maryland, \\ College Park, Md., USA
}

\section{Key Words}

Surgeon-patient communication • Information disclosure • Nigeria

\begin{abstract}
Objective: This study examined the practice of information disclosure to patients by surgeons in Nigeria. Subjects and Methods: A 55-item self-administered semi-structured questionnaire was sent to 150 surgeons in southwestern $\mathrm{Ni}$ geria in 2004-2005. The data obtained from the completed questionnaire were analyzed using descriptive statistics. $\boldsymbol{R} \boldsymbol{e}$ sults: Of the 150 surgeons, 102 completed the questionnaire, giving a response rate of $68.0 \%$. Of these $102,85(85.3 \%)$ were men, 44 (43.1\%) were consultants and 55 (54.0\%) were senior and junior surgical trainees. Most were from surgical subspecialties and obstetrics and gynecology. A documented policy statement about information disclosure was not available in most hospitals. A third, i.e. 35 (34.3\%), of the surgeons did not routinely engage patients in discussions about disease diagnosis, management and prognosis. Most, i.e. 73 (71.6\%), would rather disclose worsening disease progression to the patient's spouse. Others would disclose such information to the patient's children, family members or clergy. This was presumably to shield the patient from psychological distress. Only 22 (21.6\%) of them routinely disclose
\end{abstract}

operative findings to patients or their families. Thirty (29.4\%) of them had been involved in disclosing medical errors to their patients in the past while $63(61.8 \%)$ respondents did not know if surgical errors with potentially negative consequences should be disclosed. Conclusion: Most of the surgeons in southwestern Nigeria did not routinely provide detailed information to patients about their illness and possible outcome of illness even in the presence of worsening disease progression and prognosis. When surgical errors with potential negative consequences occurred, the majority did not know if such errors should be disclosed.

Copyright $\odot 2011$ S. Karger AG, Basel

\section{Introduction}

Information flow between physicians and patients is fundamental to building a strong professional relationship and is vital to enhancing the trust and confidence of patients in their physicians. With respect for persons as a central theme in modern medical practice comes a patient-centered physician-patient relationship that is based on trust and is nurtured by skillful communication. Communicating essential information to the patient is fundamental in surgical practice compared to other clinical disciplines. Ethically sound surgical practice requires

\section{KARGER \\ Fax +4161306 1234 \\ E-Mail karger@karger.ch}

www.karger.com
C 2011 S. Karger AG, Basel

$1011-7571 / 12 / 0213-0238 \$ 38.00 / 0$

Accessible online at:

www.karger.com/mpp
Dr. Temidayo O. Ogundiran

Division of Oncology, Department of Surgery

University College Hospital

PMB 5116, Ibadan (Nigeria)

Tel. +234803 715 5946, E-Mail toogundiran@yahoo.co.uk 
Table 1. Demographic and professional characteristics of the 102 surgeons in the study

\begin{tabular}{|c|c|c|}
\hline & $\mathrm{n}$ & $\%$ \\
\hline \multicolumn{3}{|l|}{ Age } \\
\hline$\leq 30$ years & 9 & 8.8 \\
\hline $31-40$ years & 60 & 58.8 \\
\hline $41-50$ years & 28 & 27.5 \\
\hline $51-60$ years & 5 & 4.9 \\
\hline \multicolumn{3}{|l|}{ Sex } \\
\hline Male & 87 & 85.3 \\
\hline Female & 11 & 10.8 \\
\hline Sex not stated & 4 & 3.9 \\
\hline \multicolumn{3}{|l|}{ Type of institution } \\
\hline Tertiary & 90 & 88.2 \\
\hline Secondary & 6 & 5.9 \\
\hline Private & 3 & 2.9 \\
\hline Others & 3 & 2.9 \\
\hline \multicolumn{3}{|l|}{ Status } \\
\hline Consultant & 44 & 43.1 \\
\hline Senior registrars & 22 & 21.6 \\
\hline Registrars & 33 & 32.4 \\
\hline Others & 3 & 2.9 \\
\hline \multicolumn{3}{|l|}{ Duration of practice } \\
\hline$<5$ years & 65 & 63.7 \\
\hline $5-10$ years & 24 & 23.5 \\
\hline$>10$ years & 9 & 8.9 \\
\hline Duration not stated & 4 & 3.9 \\
\hline \multicolumn{3}{|l|}{ Specialty } \\
\hline Surgical subspecialties & 28 & 27.4 \\
\hline General surgery & 27 & 26.5 \\
\hline Obstetrics and gynecology & 22 & 21.6 \\
\hline Otorhinolaryngology & 5 & 4.9 \\
\hline Ophthalmology & 5 & 4.9 \\
\hline Dentistry & 5 & 4.9 \\
\hline Others & 8 & 7.8 \\
\hline Specialty not stated & 2 & 2.0 \\
\hline \multicolumn{3}{|l|}{ Location of practice } \\
\hline Lagos & 11 & 10.7 \\
\hline Southwest (outside Lagos) & 76 & 74.5 \\
\hline Southeast & 4 & 3.9 \\
\hline North-central & 4 & 3.9 \\
\hline Northeast & 2 & 2.0 \\
\hline Southsouth & 2 & 2.0 \\
\hline Not stated & 3 & 3.0 \\
\hline
\end{tabular}

indispensable bedside communication skills and forthrightness in providing adequate clinical information to patients. It also necessitates providing a favorable environment for mutual physician-patient interaction.

Significant improvements seem to have been made in doctor-patient interactions and communication in western societies. The situation seems to be different in developing countries where medical practice is still largely pa- ternalistic and significant socioeconomic and power differential exist between physicians and patients.

There are not many studies in Nigeria that have asked surgeons about the details of information that they provide to their patients in clinical practice. Some previous studies documented the quality of the surgical consent process from the perspective of patients [1-4]. In this paper, we report the results of a survey among Nigerian surgeons on communication between them and their patients. In a previous publication, we reported the opinions of the surgeons and their practice of informed consent from data obtained from the same survey [5].

\section{Subjects and Methods}

The study was designed to elicit information about surgeonpatient communication from practicing surgeons in southwestern Nigeria. A questionnaire containing semi-structured and open-ended questions was designed and pilot tested among resident surgical trainees at the University College Hospital, Ibadan, Nigeria. The final version of the questionnaire was distributed by personal contact to both the surgeons and surgical trainees at the University College Hospital Ibadan and in some randomly selected cities and towns in Nigeria in 2004-2005.

The questionnaire, a 55-item document, was structured into seven categories. The first section asked about demography, surgical specialty, status, type of practice and area of practice of the respondents. The second set of questions elicited information about informed consent process and practice. The next three sections focused on information about disease diagnosis and management, surgical operative procedures and postoperative communication. The last two sections requested information about surgical error disclosure and how to improve the surgeon-patient communication process. The respondents were to select as many options as necessary. The data obtained were analyzed using descriptive statistics with SPSS software version 13.

\section{Results}

Information about the demographic and professional characteristics of the surgeons is given in table 1 . Of the 102 respondents, $90(88.2 \%)$ were from tertiary level teaching hospitals and the rest were from general and private hospitals. Many, i.e. 60 (58.8\%), were aged 31-40 years; 87 (85.3\%) were males; 44 (43.1\%) were of the consultant grade, and 55 (54.0\%) were senior and junior surgical trainees. At the time of the survey, 65 (63.7\%) respondents had been in practice for less than 5 years and only $9(8.9 \%)$ had practiced for more than 10 years. By specialty distribution, the respondents were from general surgery [27 (26.5\%)], other core surgical subspecialties 
combined [28 (27.4\%)] and obstetrics and gynecology [22 (21.6\%)]. The core surgical subspecialties represented in the study included orthopedics [11 (10.8\%)]; plastic and reconstructive surgery [6 (5.9\%)], and pediatric surgery [4 (3.9\%)]. Seven $(6.8 \%)$ of them were from cardiothoracic, urologic and neurosurgical subspecialties. Eight of the respondents did not indicate their specialty. Most respondents were from the southwest, and only $12(11.8 \%)$ were based in other regions of the country.

\section{Disclosure of Information}

Concerning policy on communication of clinical information to patients, 49 (48.0\%) surgeons stated that their hospitals did not have any documented policy while $22(21.6 \%)$ did not know if any policy existed. As to the necessity of such document, the majority, i.e. 84 (82.4\%), did not know if documented policy was necessary. As a general practice in clinical discussions, $23(22.5 \%)$ of the surgeons disclosed to their patients the information that they (the surgeons) considered to be positive. The same percentage would disclose both what they considered positive and some grave information, while 24 (23.5\%) disclosed all information that they thought the patients should be aware of whether good or bad news. On the ethics behind nondisclosure, 36 (35.3\%) respondents did not consider it unethical while 54 (52.9\%) did not know whether it was ethical or not when all information about a person's illness is not disclosed to him or her. When asked about the principles that should guide policy on disclosure of information to patients, they mentioned right to information, disclosure of necessary information and sincerity among others.

\section{Routine Full Disclosure of Diagnosis, Management and Prognosis}

A third, i.e. 35 (34.3\%), of the surgeons did not routinely discuss directly overall disease diagnosis, management options and prognosis with patients or their families. Even in the presence of worsening disease progression and poor prognosis, $58(56.9 \%)$ would hesitate to discuss this with their patients. Some of the reasons given for nondirect disclosure to patients include the need to protect patients from psychological trauma, prognostication is sometimes inaccurate, and the tendency of such information to hasten patients' demise. They would rather discuss such information with the patient's spouse [73 (71.6\%)]; mature children [69 (67.6\%)]; other mature family members [45 (44.1\%)]; patients' surrogates or representatives [44 (43.1\%)], or the patient's clergy [29 $(28.5 \%)]$.
Request by Family Members to Withhold Information from Patients

Relatives of patients sometimes request that surgeons should not pass some or all medical information directly to the patients but to them. Seventy-three (71.6\%) of the surgeons agreed that relatives did make such requests and $19(18.6 \%)$ others actually considered it to be a frequent request from patients' family members. While 49 (48\%) surgeons would rarely accommodate such a wish by relatives, another 34 (33.3\%) said that they often acceded to such requests. When asked about the category of patients that family members would commonly request that medical information be withheld from, their responses were elderly patients [65 (63.7\%)]; terminally ill patients [66 (64.7\%)]; patients with grave prognosis [71 (69.6\%]; mentally impaired patients [39 (38.2\%)]; female patients [34 $(33.3 \%)]$, and pediatric patients [29 (28.4\%)]. The most important reasons given why family members made such requests were the desire to protect patients from grave information that is perceived to be psychologically harmful to them and the fact that it is not culturally acceptable to pass such medical information directly to patients. Whatever the reason(s), only 19 (18.6\%) of the surgeons accepted it to be ethically correct to grant the request while 49 (48\%) considered it unethical.

\section{Postoperative Communication}

One fifth, i.e. 22 (21.6\%), of the respondents answered 'yes' and 59 (57.8\%) answered 'no' to the question 'do you routinely disclose operative findings to your patient or his/her family?.' The remaining surgeons left the question unanswered. Answering a similar question, i.e. 'should the surgeon routinely discuss detailed operative findings with the patient or his family?', 11 (10.8\%) and 17 (16.7\%) surgeons responded 'yes' and 'no', respectively, while the majority, i.e. 66 (64.7), responded 'don't know'. When asked a more specific question about how often they had disclosed ominous operative findings to patients or family members, 14 (13.7\%) had done it commonly, 65 (63.7\%) seldom, and 18 (17.6\%) had never done so. The reasons why the surgeons were not likely to disclose detailed operative findings to their patients or their family members are given in table 2 .

\section{Disclosure of Surgical Error}

About one third of the surgeons each responded 'yes' [30 (29.4\%)], 'no' [32 (31.4\%)], or 'cannot remember' [33 $(32.4 \%)]$ to the question 'have you ever disclosed any iatrogenic error you committed to your patient before?'. When further asked about how often such error disclo- 
Table 2. Reasons why the surgeons may not disclose detailed operative findings to patients or their families

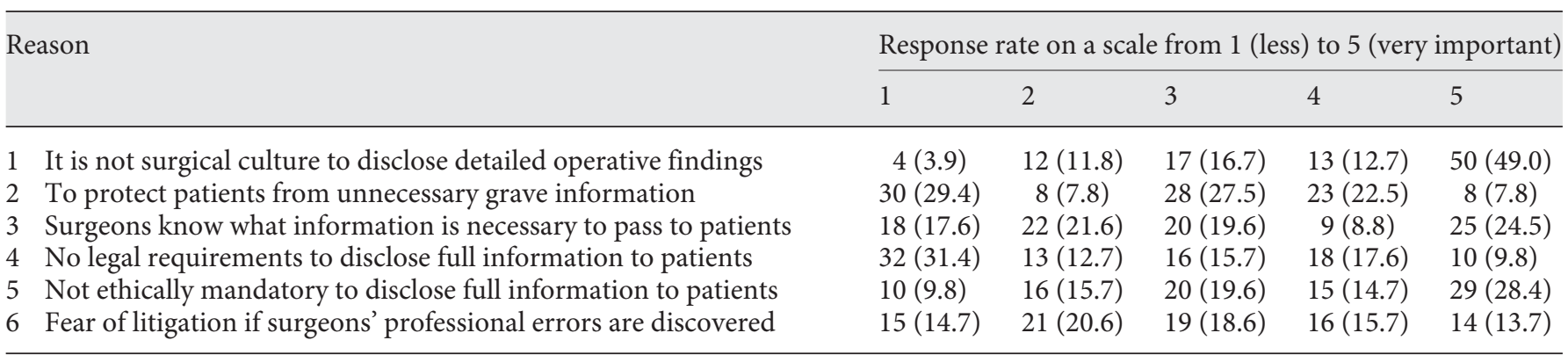

Figures in parentheses are percentages.

Table 3. The surgeons' responses to the question 'To whom should surgical errors be disclosed?'

\begin{tabular}{llccl}
\hline \multirow{2}{*}{ Recipient } & \multicolumn{2}{l}{ Response } & \\
\cline { 3 - 5 } & yes & no & don't know \\
\hline 1 & The patient & $16(15.7)$ & $16(15.7)$ & $64(66.7)$ \\
2 & The patient's family & $31(30.4)$ & $34(33.3)$ & $31(30.4)$ \\
3 & Surgical colleagues & $5(4.9)$ & $9(8.8)$ & $84(82.4)$ \\
4 & Hospital ethics committee & $23(22.5)$ & $16(15.7)$ & $56(54.9)$ \\
5 & Hospital management & $22(21.6)$ & $26(25.5)$ & $41(40.2)$ \\
6 & At clinical meetings & $2(2.0)$ & $5(4.9)$ & $84(82.4)$ \\
\hline
\end{tabular}

Figures in parentheses are percentages.

sures were made outside the routine departmental reviews or morbidity and mortality meetings, the response was 'never' [7 (6.9\%)], 'seldom' [29 (28.4\%)], and 'commonly' [46 (41.1\%)]. However, to the question 'do you agree that surgical errors of commission or omission with potentially negative consequences for the patient be disclosed to him/her?', only 18 (17.6\%) agreed and 17 (16.7\%) disagreed, while the majority, i.e. 63 (61.8\%), responded that they did not know. The surgeons' response about who they should report their surgical errors to is shown in table 3. Thirty-one (30.4\%) of them preferred to disclose to the patients' families, $23(22.5 \%)$ to the hospital ethics committee and $22(21.6 \%)$ to the hospital management. They listed transparency, voluntariness, willingness to improve the system, fairness, discretion and the aim to prevent similar occurrences as principles that should guide surgical error disclosure. The top benefits and risks that the respondents listed as potential outcomes of a policy of routine surgical error disclosure are given in table 4.

\section{Discussion}

Information disclosure by the doctor to the patient is one of the pillars on which virile doctor-patient relationship rests. This study showed that most of the participants did not routinely provide relevant clinical information to their patients. Those who discussed with their patients provided only the information that they considered positive and left out others. Their main premise was that full disclosures might adversely affect the patients. These findings are similar to a study among different cadres of surgeons in the UK [6]. However, another study showed that the surgeons underestimated their patients' need for detailed perioperative information [7]. Illness creates a state of vulnerability in which the sick looks up to the healer for help and holds the healer as the repository of needed knowledge, skill and expertise to be deployed for her cure. That attitude, perhaps, shaped the patient-doctor relationship for long and created subtle information imbalance in which the patients seemed to be contented with little or no facts about their illnesses and means of cure for as long as the needed relief was achieved. Thus, traditionally, information flow between physicians and patients has been known to be less than satisfactory as corroborated by a review in which doctors underestimated their patients' need for information in $65 \%$ of clinical encounters [8].

A third of our respondents disclosed that they did not routinely provide information on diagnosis, management and prognosis to their patients. This may be a common practice in many developing countries where clinical interactions between surgeons and patients are often scanty and short. This communication gap between surgeons and their patients has been the subject of many empirical studies in some parts of the world. In an interview 
Table 4. Top 7 potential benefits and risks of disclosing iatrogenic errors listed by the surgeons

\begin{tabular}{ll}
\hline Potential benefits & Potential risks \\
\hline Enhances learning from such errors & Litigation and prosecution \\
Prevention of further complications & Negative impact on practice \\
Promotes honesty and openness & Loss of trust and confidence \\
Promotes trust and confidence & Hospital sanction \\
Reduces likelihood of litigation & Loss of license \\
Frees the conscience & Undue patient anxiety \\
Practice is improved & Assault on personnel \\
\hline
\end{tabular}

of 155 patients who underwent gynecologic procedures in two tertiary institutions in Bangladesh, the surgeons explained the diagnosis to only $31 \%$ of them, and $75 \%$ of the patients never talked with their surgeons [9]. Moreover, Pérez Castanedo et al. [10] reported that while $60 \%$ of surgeons in a survey reported providing information on surgical risks to patients, only $51 \%$ of the patients reported that they were so informed. These studies, and ours, highlight the dichotomy between surgeons' practices and patients' expectations about information dissemination both before and after surgical management. The nondisclosure could be due to a lack of significant regulatory oversight of the process that specifies a minimum standard or protocol of information dissemination to which the surgeons can be held accountable. This is made manifest in this study because about half of the participants in this survey stated that their hospitals did not have a documented policy on information disclosure and many more $(82.4 \%)$ did not know if a documented policy was necessary. This study, therefore, highlights the need for effective policies on communication and information disclosure to patients.

Selective disclosure of information by surgeons is often predicated on the perceived impression that detailed clinical information results in information overload that leaves the patient overwhelmed, confused and perhaps, harmed. In this study, almost two thirds of the surgeons did not discuss bad prognosis or worsening disease progression with their patients. Equally important, a third of them withheld passing medical information directly to their patients on family members' request. This finding is apparently supported by an international five-country survey of breast cancer patients and their physicians [11] in which $63 \%$ of the physicians thought that the patients were overwhelmed by the amount of information available to them, while in fact only $16 \%$ of the patients felt overwhelmed. In general, surgeons are sometimes faced with the dilemma of providing adequate information in a nonmaleficent manner as shown in a study by McCahill et al. [12]. The study showed that one of the most common ethical issues cancer surgeons encountered was how to disclose information to patients truthfully and without shattering their hope.

About $70 \%$ of respondents in this survey would withhold declaring grave prognosis to their patients. Protection from psychological harm and inconsistency with cultural norms were among the reasons the surgeons cited for keeping back information about bad prognosis from their patients. Sometimes, surgeons withhold such critical medical information from patients on the request of family members and relatives. The thinking behind this is to protect the patient from undue emotional distress and psychological harm. In such situations, family members may not fully explore or comprehend the full ramifications of nondisclosure to the patient [13]. In a population survey exploring how much information healthy Japanese would expect from their doctors in the event they developed cancer, Miyata et al. [14] reported that $84.5 \%$ of the respondents wanted full disclosure of diagnosis. Moreover, more than half of them, i.e. 55.3\%, would like to obtain diagnosis and prognosis information ahead of their family.

In 'medical practice, mistakes are common, expected and understandable' $[15,16]$. Medical errors can be an omission or a commission arising from deficiencies in a physician's knowledge, skill or inattentiveness or from flaws in the system of practice [17]. As shown in the study of Krizek [18], of a total of 2,183 adverse errors, $10.5 \%$ of them were directly surgery related. The incidence of surgical errors among the surgeons in our study was not determined. However, a third of them had been involved in disclosing iatrogenic errors to their patients. Furthermore, about two thirds of them did not think that it was necessary to disclose errors with potentially negative consequences to patients. To our knowledge, there are no published empirical works on medical error 
disclosure in Nigeria. Most respondents in a survey of 557 pediatricians and pediatric residents in Washington in the USA had been involved in errors of varying degrees and more than $80 \%$ of them endorsed the need to report errors to the hospital [19]. A similar but crosscountry survey among physicians in Canada and the USA reported that $98 \%$ of them endorsed reporting serious errors to patients while $58 \%$ of them had reported at least a serious error to a patient [20]. The rationale for the position of our respondents was not explored in this study. However, a medical culture has not evolved to appreciate that medical errors can occur even with the best intentions and therefore, the system tends to overreact and is often adversarial when errors occur. Most probably, this could be due to the fact that errors are personalized and the system treats all errors as a failure of character. Therefore, the tendency is for physicians to let most errors lie low or remain unreported. The drawbacks of this study were that it was limited to mostly southwestern Nigeria and the preponderance of surgical trainees most of whom had been in surgical practice for only 5 years or less.

\section{Conclusion}

The results from this survey revealed communication inadequacies between the surgeons and patients. Most of the surgeons did not routinely provide detailed information to patients about their illness and possible outcome of illness even in the presence of worsening disease progression and prognosis. When surgical errors with potential negative consequences occurred, the majority did not know if such errors should be disclosed. These findings have implications for the training of medical students and residents and also underscore the need for periodic update workshops on effective communication skills for all surgeons.

\section{Acknowledgements}

The authors thank the research staff in the Division of Oncology, Department of Surgery, University College Hospital, Ibadan who distributed the questionnaires. The study was partly supported by funds from Fogarty re-entry grant from the Joint Centre for Bioethics, University of Toronto, Ont., Canada.

\section{References}

-1 Osime OC, Okojie O, Osadolor F, Mohammed S: Current practices and medico-legal aspects of pre-operative consent. East Afr Med J 2004;81:331-335.

$\checkmark 2$ Aisuodionoe-Shadrach OI, Ogunlade OS, Amoran OE: An evaluation of the informed consent process for elective surgery at a university hospital. Niger J Med 2006;15:281284.

$\checkmark 3$ Adisa AO, Onakpoya UU, Oladele AO, Lawal OO: Informed consent in surgery: an audit of practice in Ile-Ife, Nigeria. Niger J Clin Pract 2008;11:206-210.

4 Jebbin NJ, Adotey JM: Informed consent: how informed are patients? Niger J Med 2004;13:148-151.

-5 Ogundiran TO, Adebamowo CA: Surgeons' opinions and practice of informed consent in Nigeria. J Med Ethics 2010;36:741-745.

6 Burton MV, Parker RW: Psychological aspects of cancer surgery: surgeons' attitudes and opinions. Psychooncology 1997;6:4764.

7 Keulers BJ, Scheltinga MRM, Houterman S, Van Der Wilt GJ, Spauwen PHM: Surgeons underestimate their patients' desire for preoperative information. World J Surg 2008;32: 964-970.
8 Waitzkin H: Doctor-patient communication. Clinical implications of social scientific research. JAMA 1984;252:2441-2446.

$\checkmark 9$ Khanam NN, Alam H, Akhter S: Ethical awareness in surgical management. Mymensingh Med J 2010;19:360-365.

$>10$ Pérez Castanedo J, Hernando Robles P, Cañellas Arsegol M, Barrena Vilà A, Font Renom J, González Alvarez I: Information about operative risk: opinions of the physicians and patients involved. Rev Esp Anestesiol Reanim 2004;51:20-27.

-11 Lansdown M, Martin L, Fallowfield L: Patient-physician interactions during early breast-cancer treatment: results from an international online survey. Curr Med Res Opin 2008;24:1891-1904.

12 McCahill LE, Krouse RS, Chu DZ, Juarez G, Uman GC, Ferrell BR, Wagman LD: Decision making in palliative surgery. J Am Coll Surg 2002;195:411-422.

13 Angelos P, Lafreniere R, Murphy TF, Rosen $\mathrm{W}$ : Ethical issues in surgical treatment and research. Curr Probl Surg 2003;40:353-448.

14 Miyata H, Tachimori H, Takahashi M, Saito T, Kai I: Disclosure of cancer diagnosis and prognosis: a survey of the general public's attitudes toward doctors and family holding discretionary powers. BMC Med Ethics 2004;5:E7.
15 Brennan TA, Leape LL, Laird N, et al: Incidence of adverse events and negligence in hospital patients: results of the Harvard Medical Practice Study II. N Engl J Med 1991;324:370-376.

16 Leape LL: Error in medicine. JAMA 1994 272:1851-1857.

17 Wu AW, Cavanaugh TA, McPhee SJ, Lo B, Micco GP: To tell the truth: ethical and practical issues in disclosing medical mistakes to patients. J Gen Intern Med 1997;12:770-775.

18 Krizek TJ: Surgical error: ethical issues of adverse events. Arch Surg 2000;135:1359-1366.

19 Garbutt J, Brownstein DR, Klein EJ, Waterman A, Krauss MJ, Marcuse EK, Hazel E, Dunagan WC, Fraser V, Gallagher TH: Reporting and disclosing medical errors: pediatricians' attitudes and behaviors. Arch Pediatr Adolesc Med 2007;161:179-185.

20 Gallagher TH, Waterman AD, Garbutt JM, Kapp JM, Chan DK, Dunagan WC, Fraser VJ, Levinson W: US and Canadian physicians' attitudes and experiences regarding disclosing errors to patients. Arch Intern Med 2006;166:1605-1611. 